\title{
Clicks-and-bricks: a case study of the Amaro brand
}

\begin{abstract}
The rise of e-commerce has dematerialized retail shopping locations, transposing them to the digital layer in the so-called 'brick-to-click' movement. However, the opposite path, 'click-and-brick', arouses curiosity for the re-association of the physical store with e-commerce, directing attention to new meanings of materiality in fashion retail. In this context, this paper discusses the multidimensional materiality of fashion retail within the e-commerce theme from two main movements: the emergence of physical spaces that complement online stores and the orientation of e-commerce operations towards big data. To illustrate the concepts and reflection on these themes, the authors carry out a case study on the omnichannel operations of a brazilian fashion brand called AMARO.
\end{abstract}

Volume 7 Issue 6 - 202I

\author{
Maíra Nicoletti \\ Universidade do Vale do Rio dos Sinos, Brazil
}

Correspondence: Maíra Nicoletti, Universidade do Vale do Rio dos Sinos, Brazil, Email mairaanicoletti@gmail.com

Received: November 24, 202I | Published: December 08, 2021

Keywords: e-commerce, fashion retail, fashion marketing

\section{Introduction}

The emergence of e-commerce has dematerialized retail shopping locations, transposing them to the digital layer in the so-called 'brickto-click' movement, ${ }^{1}$ where physical retail operations create their online retail presences with gains of scale. However, physical stores still offer a multidimensional shopping experience that is relevant to customers, perhaps irreplaceable. Such multi-sensory retail would offer an opportunity to fully engage consumers, but it would not be as easily replicable online as in the physical environment. ${ }^{2}$ Because of this, the opposite path, 'click-and-brick', arouses curiosity for the reassociation of the physical store with e-commerce, directing attention to new meanings of materiality in fashion retail. Such physical-digital hybridity translates into multidirectional movements: while online retailers recognize the limitations of the digital layer to translate the sensitive dimensions of a physical object, they also appropriate data science to understand the behavior of their consumers. ${ }^{1,3}$ Is fashion retail therefore dependent on physical materiality, even in its digital version? What kind of meaning would this new materiality, of a postdigital nature, take on? How would the topography of consumers' fingerprints influence materiality decisions in fashion retail? From guide shops ${ }^{1}$ to big data, fashion retailers invite consumers to experience the product and the brand in a multidimensional way, distributed in layers of different materials.

The fashion and apparel segment is the most expressive in terms of order volume in Brazilian e-commerce, having an expressive growth every year. Inserted in this scenario, the Brazilian brand $\mathrm{AMARO}^{2}$, which was born as an online retail operation, structured a multichannel offer with physical and digital presence associated with a fluid shopping experience, consistently investing in technology and data intelligence. Thus, this paper look at the hybrid dimensionality of 'click-and-brick' strategies in the scope of fashion retail, analyzing the case of the AMARO brand, which articulates big data and guide shops operations to its e-commerce in a flow continuous and feedback between physical and digital instances. Therefore, a qualitative case study was structured that sought to understand and interpret the business model of the AMARO brand, as well as to analyze its strategies to consolidate itself in an omni-channel retail format. Data collection took place through research and analysis of interviews and cases available in press articles.

'Physical commercial establishment with display, but without stock, in which consumers choose and taste products, buy them via totems or online tablets present in the place, and then receive the goods at home via traditional shipping. ${ }^{2}$ Amaro - www.amaro.com

\section{Online retail: a new materiality from the digital}

The digital revolution has transformed the balance of power between those who produce and those who buy, making it easier for consumers to access information about products and services. In this sense, the growth of e-commerce has brought significant advances to traditional retail, changing the perception of distance and time throughout the value chain between manufacturer and consumer. ${ }^{4}$ While most traditional retailers have extended their operations to the virtual world, others have completely migrated to online retail, abandoning physical stores. Already some more recent operations have emerged with online operations from the beginning. Companies like Net-a-Porter, which sells luxury fashion online, the british ASOS, the chinese Shein and AMARO itself have registered significant success in their operations without the presence of a physical store - in them, the retail environment is contained in a screen, mediated by interfaces on websites. Some authors argue that the success of stores operating exclusively online would be much more linked to the assortment of products than to the retail format itself., ${ }^{4,5}$ In this sense, there is a questioning of how much the materiality of the interface would be responsible for the success of the operation.

One of the biggest challenges in online retailing is translating the multi-sensory experience of the physical store through the screen of a computer or smartphone. It is a reduction in the order of stimuli provided: the combination of environmental, structural, social and aesthetic elements needs to be reduced to a predominantly visual appeal. ${ }^{4}$ Based on this, designers and retailers launch the appropriation of technology to create experiential virtual environments that offer meaningful experiences to the consumer, fostering consumer reliability, engagement and loyalty to achieve the operation's strategic objectives.

\section{The evolution of digital materiality: information technology and user experience as e-commerce structures}

If, in the early 1990s, the graphical interface provided to computer users brought graphics that simplified the complexity of machine language and mediated interactions, over the decade and after the popularization of the internet, companies and users began to create their own websites and text-filled interfaces gave way to more visual and moving compositions. ${ }^{4}$ According to some authors, ${ }^{2,6}$ interactivity, through image manipulation such as zoom or rotation, was one of the 
main benefits that information technology has brought to online retail In this sense, the feeling of consumer empowerment is increased, delivering a positive experience when viewing products online and making their usage aspects tangible, which contributes to consumer loyalty. ${ }^{2}$

With the advent of technological innovations that came to be called Web 2.0, there was an increase in interaction between users through blogs and social media, which resulted in a more dynamic and interconnected user experience. It is possible to affirm that the simplification of information sharing allowed the interaction of companies with consumers in a more direct way, facilitating socialization between consumers and companies., ${ }^{2,4}$ The technological advance that was called Web 3.0 - the "intelligent web" - brought to light the reality of artificial intelligence through the exchange of information between user and machine through semantic networks, data mining and intelligent recommendations. ${ }^{4}$ Big data, combined with powerful analytics systems, allows a deep understanding of consumers through surveys, comments, likes and, above all, browsing history and behavior. At the same time, advances in wireless connectivity, from the so-called Web 4.0, have increased the convenience of delivering the offering to consumers, where interaction and location interfaces are easily accessed through smart mobile devices. Especially in the field of fashion, applications provide content and connection to social media and other channels, enabling social interactions between users and the brand. ${ }^{4}$

The evolution of information technology in terms of connectivity and devices allows for the personalization of the online shopping journey, the two-dimensional brand-consumer and consumerconsumer interaction and the generation of experiential value. However, the boundary of experiences between physical and digital retail persists: online retail cannot replicate all the sensory experiences of the physical store, both in terms of tangible aspects of the space and product, and intangibles such as sound, smell and lighting., According to Kent, ${ }^{8}$ the physical store is still configured as the main point of contact between the user and the brand - the multi-sensory experience of the physical store makes the user perceive the product, service and brand in a continuous and integrated way. In this context, Wallace et al. ${ }^{9}$ claims that, with more services and touch points, consumers would have more opportunities to engage with a company, increasing their satisfaction, trust and loyalty to the company. The multichannel company model, in this sense, would be the future of fashion retail.

\section{Click-and-brick: when digital generates a physical store}

As previously mentioned, from the 1990 s onwards, the extension of physical retailing to online retailing, the complete migration from physical retailing to e-commerce and the emergence of purely online retail operations was noticed. However, a growing number of online retailers recognized that uncertainty about product attributes would be a barrier to purchase. In addition, consumers would have less tangible information about purely online retailers, which could undermine their credibility. ${ }^{1,5}$ Therefore, companies hitherto purely online have resorted to the opposite movement: the extension of online retail to physical retail, called click-and-brick. ${ }^{1}$ As a result, some online retailers have experimented with physical store openings to reduce barriers associated with offline product features, creating a point of contact and offline experience model to engage consumers, improve brand exposure and perception, and foster credibility. ${ }^{1}$ These undertakings were characterized by their experimental nature: the formula to be followed did not copy previous physical stores, but tried to respond to the gaps that digital had exposed.

The click-and-brick movement has historically taken the form of showrooms, pop-up stores or "click and collect", where the purchase is online but the consumer picks up the product in a physical store. ${ }^{1}$ In 2012, aware that clothing size and modeling are significant obstacles in fashion e-commerces, the North American retail operation Bonobos opened its first guide shop. Guide shops, according to Bonobos $\mathrm{CEO},{ }^{1}$ are small experiential stores with individual service, where the consumer is invited to try the entire assortment of products in the virtual store. Guide shops do not have stock - the consumer tries the product, purchases online and receives the product at home. The click-and-brick format allows retailers to offer varied services and more touch points between company and consumer, strengthen the brand image, increase profitability, reduce costs and gain efficiency in marketing actions. ${ }^{5}$ In other words, the physical store created by the virtual store is hybrid in materiality - it does not exist without the digital layer, but it greatly qualifies the total consumer experience with the brand and optimizes resources with a view to its financial result.

\section{Case study: Amaro brand}

Founded in 2012 by partners Dominique Oliver, Lodovico Brioschi and Roberto Thiele, AMARO is a women's fashion brand born in a post-digital world and practicing an omni-channel retail strategy. ${ }^{10}$ Positioned within the fast fashion segment, the brand creates, develops and sells clothes, shoes and accessories at competitive prices - its offer to the market covers around ten thousand products per year, and it is important to point out that, from design to manufacturing, all production activities are carried out within Brazil. ${ }^{11}$ The brand's collections are organized into product lines that include casual, sports and executive clothing, as well as beachwear and underwear. In 2020, the brand also became a marketplace, offering products from small brazilian fashion brands that do not have the online structure to sell their products. From its foundation to the present day, Amaro's digital presence and operations have become a reference in the Brazilian fashion market. Thus, this paper will analyze and discuss the physical presence undertaken after Amaro's digital presence, consolidated as guide shops, and the big data operation focused on inventory predictability, one of the biggest strategies of the brand.

After two years of operation exclusively through its e-commerce, AMARO inaugurated, in 2015, its first "guide shop" - concept physical store that offers in-person experiences of the consumer with the brand - handling and testing of products, style consultancy and, for making the purchase, computers and tablets installed in the store to complete the process. Guide shops do not have stock, only a demonstration piece in the different color and size variations available on the brand's website (Terzian, 2015).

The brand's CEO states that the implementation of guide shops consisted of a strategy for AMARO consumers to have greater contact with the brand's DNA through multi-sensory experiences within the physical store. ${ }^{10}$ In addition, we sought to strengthen the digital platform beyond the electronic medium, bringing offline customers online. Physical and digital would therefore be complementary sales channels, especially in online retail companies. Guide shops would also consist of a media tool, an experience billboard, a more profitable investment than banners on social networks. ${ }^{11}$ The case of AMARO shows the creation of guide shops as aggregators of credibility to the brand, enabling consumers to resolve doubts regarding the quality, modeling and aesthetics of the product, common barriers to the first online purchase of a new brand. In 2018, one in three AMARO 
purchases would be made through guide shops, increasing the life time value by $43 \%$, a metric that means the revenue that the customer generates during their relationship with the brand, and reducing the cost of acquisition per customer. ${ }^{11}$

AMARO's strategy for creating physical spaces seems to indicate the adoption of the click-and-brick concept, connected with the trend towards the expansion of retail supported by information technology, trend research and logistical processes, and going towards what satisfies the your customer. ${ }^{12}$ In this sense, technologies would aim to improve brand processes, including pattern recognition and natural language processing applications. ${ }^{11}$ Following this trend, AMARO uses a strategy based on collecting data from its consumers through social networks, purchase route and digital transactions made by them in its e-commerce and guide shops. Purchase histories would feed a predictive analysis of the success of each part, an operation carried out through algorithms and big data. ${ }^{11}$ Thus, the company's production cycle was designed to avoid inventory leftovers due to inadequate choices in style, colors and sizes of the pieces. The investment in AMARO's supply chain model is based on the concept of predictive inventory management, or predictive inventory management- a substantial difference in relation to the practice of traditional brands, which work with elaborated collections from nine to sixteen months before launch. The AMARO model allows the system to classify the pieces in more than a hundred attributes including, among others, color, measurements, category, fabric, price or context of use. From there, the digital intelligence engine crosses the data with existing collections to define the number of parts that will be manufactured and can even predict the number of parts that will likely be sold in a given period of time. This constant flow of information allows the brand to launch items on a monthly basis, adjusted to the wishes of consumers. This strategy is enhanced by the company's logistical articulation - the only fashion brand in Brazil to have its own carrier which allows AMARO to deliver items very quickly. In some regions of the country, delivery can be made on the same day.

AMARO's data-driven technology has an impact not only on stock predictability, but also on its positioning and the personalization of its communication. Unlike traditional fashion brands, when communicating with customers, AMARO adds regional and consumer characteristics to create personalized posts on social networks and email marketing - from the arrival of the cold in a certain region of Brazil to the best pieces for each sign of the zodiac. ${ }^{11}$ This type of strategy modifies the consumer's perception of communication, making it as natural as possible and strengthening ties with the public. The data-driven at AMARO is also present in areas where the human dimension is normally predominant. The company's customer service (SAC), named "Customer Happiness", a sector in constant training to simplify the consumer's purchase process, from the search for a product in e-commerce or application until the exchange or return of the same. The process also makes use of the data recorded in the transactions to foster the relationship with customers, providing attendants with access to the purchase profile of consumers. Thus, the process contributes to increasingly fluid interactions and, consequently, to the expansion of satisfaction generated in consumers.

It is clear that AMARO has covered new territories in relation to the traditional practices of online retailing or "direct to consumer" brands in Brazil. There is a counterpoint both to the traditional format of wholesale and offline retail and to purely online retail operations - both in the systemic articulation between online sales and offline presence and in the generation and continuous evaluation of data as generative elements of intra-brand trends. The reformulation of the supply chain and the subsequent stitching of the touch points to support sales and brand consolidation make AMARO relevant for this study. ${ }^{13-15}$

\section{Conclusion}

If fashion e-commerce dematerialized shopping locations, transposing them to the digital layer in the movement called "brickto-click", ${ }^{1}$ AMARO's strategy to insert physical stores as experience points represents not only a diversification of the shopping experience, but also a re-materialization of what would be the clothing shopping experience after the emergence of omnichannel. If e-commerce changes the perception of distance and time throughout the value chain between manufacturer and consumer, ${ }^{4}$ we can add that, in the case of AMARO, e-commerce is connected to an omnichannel strategy, datadriven and endowed with agile logistical capabilities, it considerably reduced the friction inherent in the online apparel purchase process. The path traced by AMARO, 'click-and-brick', reassociates the physical store with electronic retail not as an alternative, but as a complement to an experience that is intended to be hybrid ${ }^{1,3}$ - a game of distinct and symbiotic materialities, where the efficient digital experience opens the way for the richness of sensations in the physical store.

The discussion about physical materiality in digital fashion retail is necessary and gains relevance from studies of brands such as AMARO. While it is safe to say that physical stores support the sales process by providing differentiated experiences that shift the brandconsumer relationship to other territories, it is also necessary to point out that AMARO has guide shops in only eight Brazilian cities, with the impact on consumers geographically restricted. It is not possible, therefore, to defend the dependence between the two models from the evidence collected, but rather to infer that there may be a beneficial relationship between them. Although the term "dematerialization" may be tempting when defining virtualized operations, which operate predominantly on the digital platform, the evidence collected points in another direction - that of a hybrid materiality, composed of heterogeneous layers. In this sense, the data that impacts the definition of collections and which is collected from a digital interface materiality (the consumer's navigation on the website), is as material and palpable as the guide shop's tasters' partitions. Post-digital materiality, in this sense, is as much composed of the physical as it is of layers of data that transform and re-signify it. The challenge of crossing the boundary between the quality of digital experience and its counterpart in the physical environment was overcome through an articulated overlap of these two modalities. Between the virtual and the physical store, you get the best of each of the two worlds: agility of delivery, stock predictability, tactile experience and production of meaning. 2,7

This paper brings contributions to the fashion area, as more and more brands use hybrid marketing strategies, moving between online and offline. However, this study does not allow generalizations beyond the borders researched here, opening possibilities for future investigations, with in-depth interviews with representatives of brands and consumers. Thus, the discussion covered here about the materiality of the hybrid presence of online retail - and its possible impacts - can be expanded by subsequent studies.

\section{Acknowledgments}

None. 


\section{Funding}

None.

\section{Conflicts of interest}

The authors declare there is no conflict of interest in publishing the article.

\section{References}

1. Alexander B, Kent A. Retail environments. Retail Design: Theoretical Perspectives. Oxon: Routledge; 2017.

2. Tse T, Tung TL. From clicks-and-bricks to online-to-offline In: Petermans A, Kent A, editors. Retail Design: Theoretical Perspectives. Oxon: Routledge; 2017.

3. Grewal D, NordfÄlt AL. The future of retailing. Journal of Retailing. 2017;93(1):1-6.

4. Vazquez D, Kent A. Online retail design. In: Petermans A, editor. 2017.

5. Toufaily E, Souiden N, Ladhari R. Consumer trust toward retail websites: Comparison between pure click and click-and- brick retailers. Journal of Retailing and Consumer Services. 2013;20(6):538-548.

6. Mccormick H, Livett C. Analysing the influence of the presentation of fashion garments on young consumers' online behaviour. Journal of Fashion Marketing and Management: An International Journal. 2016;16(1):21-41.
7. Petermans A. Retail design in the experience economy: conceptualizing and 'measuring' customer experiences in retail environments. Hasselt: Doctoral tesis. Hasselt University. 2012.

8. Kent A. Retail design: theoretical perspectives. Oxon: Routledge; 2017.

9. Wallace DW, Giese JL, Johnson JL. Customer retailer loyalty in the context of multiple channel strategies. Journal of Retail. 2004;80(4):249263.

10. Gargaro L. From online to offline: Amaro expands digital strategy with Guide Shops in São Paulo and Rio de Janeiro. 2016.

11. Fonseca M. Fashion of the future: at Amaro, your next outfit is hidden in your smartphone. 2018.

12. Sayeg C, Dix L. Fashion product management. São Paulo: Estação das Letras e Cores; 2015.

13. Dillon S. Fashion business management principles. Rio de Janeiro: Gustavo Gilli; 2015.

14. Kent Tony. 2D23D: Management and design perspectives on retail branding. International Journal of Retail \& Distribution Management. 2003;31(3):131-142.

15. Toufaily E, Pons F. Impact of customers' assessment of website attributes on e-relationship in the securities brokerage industry: A multichannel perspective. Journal of Retailing and Consumer Services. 2017;34:58-69. 